\title{
CONCEPTUAL DEVELOPMENT OF HUMAN CAPITAL
}

\author{
Ana -Maria CIUHU \\ VALENTINA VASILE
}

\begin{abstract}
This paper aims in presenting the development of human capital concept from the perspective of labour market. The starting point of the conceptual framework was the strictly quantitative approach. In the taylorists view, the labour force was considered a classical production factor. Afterwards the so-called transitional period included some qualitative attributes as contributing to labour performance. Ultimately, the human capital concept has developed within an integrative approach, in which the education and skills have a valuable position, where intangible attributes of labour forces become the main determinants of firms' competitiveness. The study proposes a conceptual mark between potential and real human capital, including the quatitative and qualitative components. The potential human capital is activated on the labour market and capitalized as real human capital. Moreover, we propose a mathematical approach of the economic rate of human capital return, based on the real and potential delimitation.
\end{abstract}

Keywords: Human capital, Labour force, Economic rate of return

JEL Classification: E24, J24, O15

\section{Introduction}

The concept of human capital has a relatively recent development. It emerged in the twentieth century (Schultz, 1961). The concept has given rise to debates, both related to significance, components, and coverage. Regarding the evolution of human capital from the perspective of the labour market, namely the transition from the exclusive quantitative approach (labour force) - to transitional concept of human resources and now as human capital, which extends the coverage through qualitative attributes of the labour production factor. The concept delimitation and economic significances and impact will be discussed.

From the perspective of the role of the labour factor in the economic processes a gradual transition can be established, from the strictly quantitative approach to the integrative one:

a) Exclusive quantitative period - the most suggestive theory is the Taylorism (Taylor, 1911), according to which labor was strictly considered a classical merchant factor, and workers were paid a fixed piece rate for each unit produced.

b) Transitional period, when organizational, qualitative attributes are gradually enrich the concept of human resources. The employment pattern specific to that period was based on the division of tasks at the company level and the strict differentiation between conception work and execution work. Employee involvement, profit participation, and potential or actual performance were also remunerated by wages and salaries. It involved the efficiency of the performance of the labor market, following the emergence of the unemployment, but also of the industrial relations. Strict regulation of minimum working conditions was required because the specificity of the labor force was detached in the production processes. In the $1950 \mathrm{~s}$, with the development of technical progress as a factor of production, there was

\footnotetext{
${ }^{1} \mathrm{PhD}$ candidate, SCOSAAR, Romanian Academy, Calea 13 Septembrie nr.13, Bucharest, Romania; Expert, National Institute of Statistics, Bd. Libertatii 16, Bucharest, Romania, e-mail: dobre.anamaria@hotmail.com

${ }^{2}$ Senior researcher I, Institute of National Economy-Romanian Academy, Romanian Academy, Calea 13 Septembrie nr.13, Bucharest, Romania, e-mail: val.vasile.ien@gmail.com

DOI: 10.29302/oeconomica.2019.21.1.5
} 
a neccesity for linking education with the labor market needs, i.e the professional skills. Thus, the labor force becomes itself an emerging factor of production, and the labor market was developed as the most regulated market.

c) Integrative approach period, in which professional education, decision-making and soft skills prevail, as factors supporting the productivity and work performance increase.

Currently, the concept of human capital (tangible and intangible) includes three dimensions: quantitative (employment indicators), qualitative (labor force allocation performance and comparative advantage of educational potential) and behavioral (industrial relations issues). The three components of the conceptual development are illustrated in the Figure 1.

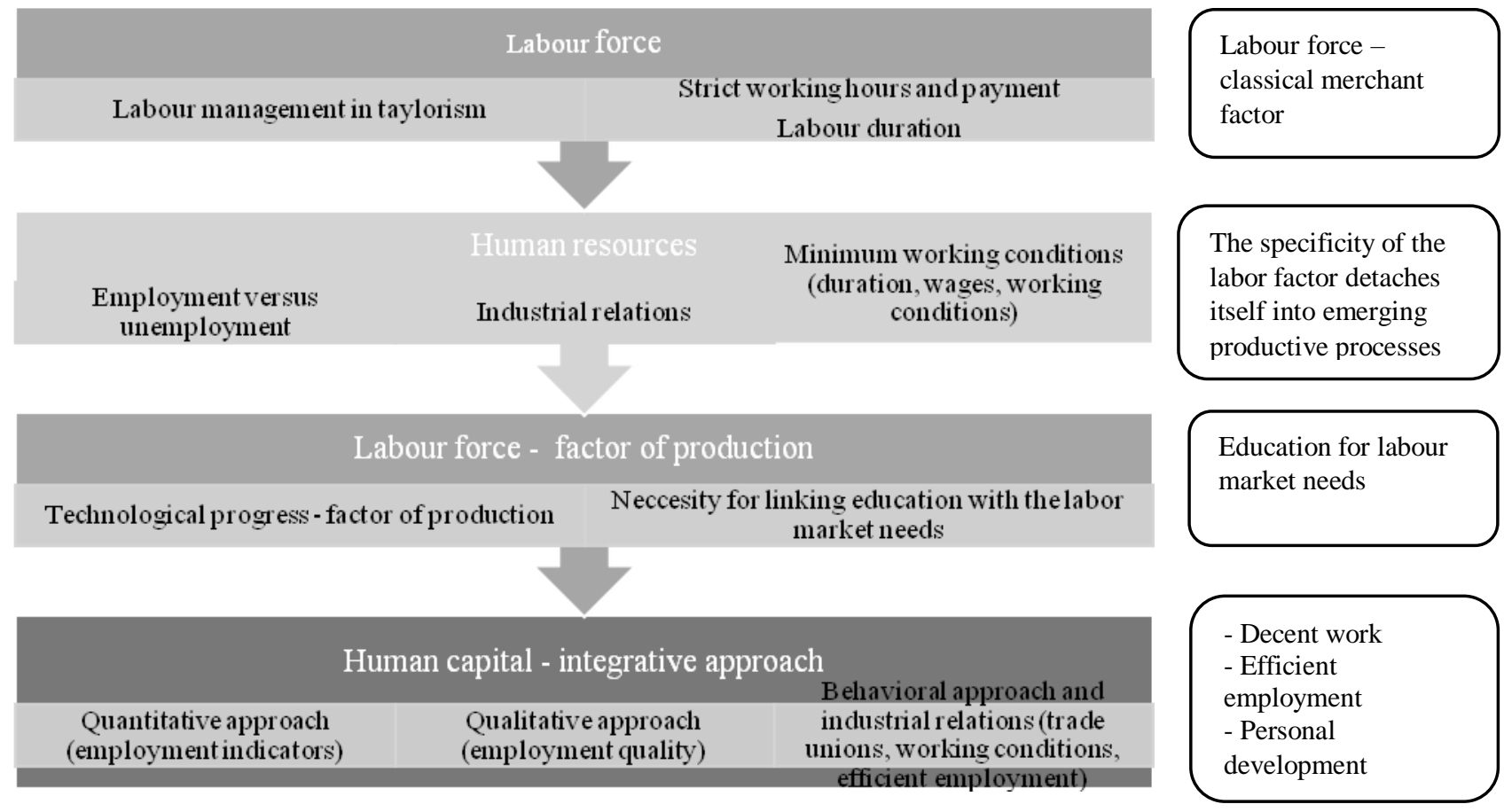

Figure 0. Human capital by labour market perspective - overview of conceptual development

Source: Synthesis based on the literature

\section{Potential vs. real human capital}

The conceptual delimitation between potential and real human capital sets out, first, from the categories of population, statistically based on the resident population. This classification includes three major age groups (under 15, 15-64 and 65 and over), and its disaggregation covers participation in economic activity. 


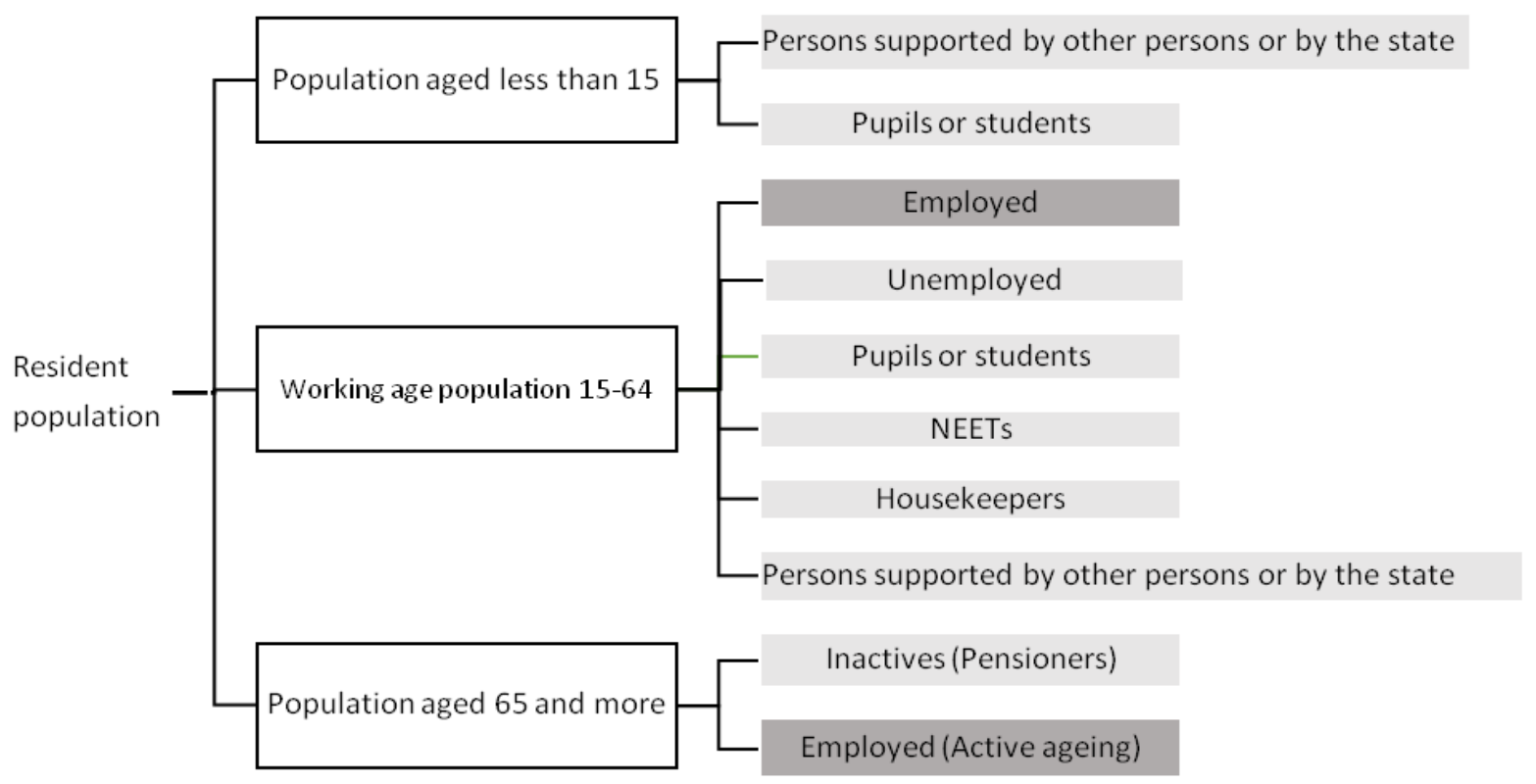

Figure 2. Categories of population

Source: Synthesis based on EU Labour Force Survey

Legend:

Employed persons (valued on the labour
market)
Inactive persons (unused on the labour market)

The potential human capital includes the working-age population (15-64 years), in a wide perspective of quantitative and qualitative attributes. The real human capital is capitalised by active involved on labour market, by employment, according both perspectives:

- Quantitative approach, in terms of number of employees, employed persons as well as the derived indicators;

- Qualitative approach, from the point of view of the matching of the qualifications with the job requirements.

Therefore, the gap between potential and real is given by the potential human capital not activated by employment and includes the following categories: unemployed, NEETs, pupils, students, homeless people, retired persons, people public social assisted or by other household members. It can be appreciated that the under-utilization of human capital on the labour market is extensive and does not refer only to the unemployed.

Real human capital includes the persons who actively participates in the labour market i.e. employees, employers, self-employed, unpaid family workers, farmers, paid apprentices and trainees, and military personnel. 


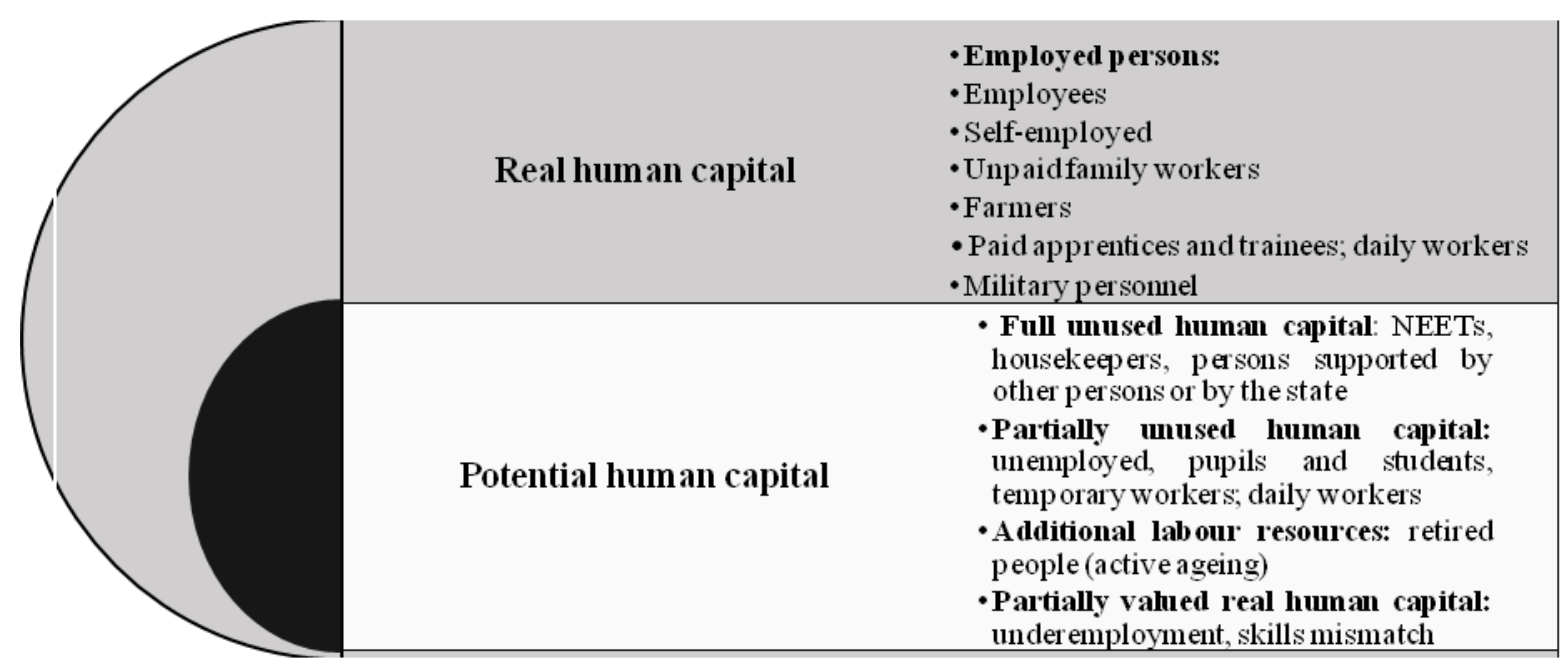

Figure 3. Categories of potential and real human capital - quantitative approach

Source: Authors' view, synthesis based on the literature

Firstly, the human capital outflow from the labour market occurs due to social and professional circumstances. Thus, on the one hand, there are totally excluded people, such as NEETs and housekeepers. Partially unused human capital can also be defined by temporary workers, unemployed, pupils and students. On the other hand, there are additional labour resources, the older people. They can be valued on the labour market by active ageing. Some special cases may also refer to the employment surplus (the labour supply exceeds the market demand, quantitative and/or as qualitative - exceed of skills or competencies or a higher educational level than the jobs requirements) or the employment deficit (the scarcity of labour force as number of individuals available to be employed and/or a disbalance between the qualification or educational level and jobs content).

As stated above, the conceptual delimitation between potential and real human capital is based on participation in economic activity, starting from the premise that human capital capitalisation is activated by employment. In the following we will present some conceptual clarifications of the three major categories of population by labour status that supports our approach. According to ILO (1982), the population is divided into three categories that are mutually exclusive in the formal economy, while in the informal labour market they can coexist (Pisică, et al., 2012). For example, a person may be statistically listed as inactive, and in the informal economy may be a seasonal worker. In this paper we consider only the human capital capitalisation in the formal economy.

Two imbalances between potential and real human capital can be identified: depending on how potential labour force represented by graduates is absorbed into the labour market by employment and by skills mismatch. The objective of sustainability of the human capital valorisation is to minimize the gap between these two dimensions, the potential one and the real one.

In a broad approach of conceptual delimitation between the two sides of human capital (HC), real (R) and potential (P), it is recommended to translate them into mathematical formulas so as to highlight the particularities of quantitative and qualitative approaches:

1. The gap R-P, in the quantitative approach, reflects the gross human capital deficit, denoted by $D_{b}$

2. The gap R-P, in the qualititative approach, refers to the adjusted human capital deficit, denoted by $D_{a j}$

Human capital, as a difference between real and potential, is expressed by the following formulas:

$D_{a j}=\left(D_{b}+D_{e c h i v}\right)-H C(P)$

where: 


\section{$D_{\text {echiv }}=\sum \mathbb{Q}( \pm$ skills mismatch, $\mathbb{I} \pm$ overemployment, \pm underemployment $)$}

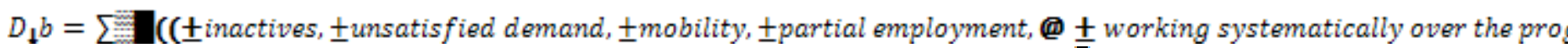

We propose to define the economic rate of human capital return $\left(\bar{R}_{H C}\right)$ by the following formula:

$$
R_{H C}=1-\frac{D_{a j}}{H C(P)}
$$

This ratio reveals the human capital translation from potential to real status.

\section{Perspectives on the conceptual development of the human capital}

In our opinion, the general principle of any society is to activate human capital on the national economy and to ensure the balance of the labor market, both quantivelly and qualitativelly and to limitate the $\mathrm{HC}(\mathrm{P})$ to migrate on international labour market. Therefore, the current challenges lie in the concern for the evolution of future work. As a result of RDI and the emergence of new business and industry models, it will tend towards matrix development of relations between social partners, business diversity, virtual organization, social responsibility and business ethics. Work transformation will be guided by new technologies and digital economy, data\&communication, social networks, and traditional activities and professions will disappear (PricewaterhouseCoopers, 2014) (Vasile, 2016).

The labor market operates on the principle of flows, but it faces a number of restrictions: legislative limitations, mobility as a balancing factor of the occupational status at the individual level (horizontal development of the career, materialized in complementary activities or mobility for work), inequality (which may sometimes lead to the loss of potential in a profession by changing the field and activity profile) and the relative flexibility of occupational forms, different in occupations (full-time versus part-time, fixed-term employment versus permanent employment and selfemployment vs. employee status).

Mobility for work, which has become very important in recent decades, will gain even greater importance in defining human capital in the future. It is the one that can present various forms that contribute to labour force balance: on the one hand, it identifies the change of the job on the same professional path (internal mobility within the profession), and on the other hand it can refer to employment by the same person in complementary jobs (mobility outside the profession).

The analysis of the characteristics of human capital in the future should consider the increase in the demand for skills and qualifications that have recently emerged on the labor market, i.e. those specific to the digital and cross-sectoral economy. While the nature of many workloads has changed, there is an increasing demand for university qualifications - the phenomenon is called "degree inflation" (Eurostat, 2016, p. 13). Specifically, it occurs when employers require a qualification merely because there is a sufficient pool of graduates to draw from. In other words, the fact that a qualification is currently required for a job is not sufficient proof that the competences certified by that qualification are indeed necessary for that job.

The future of the employment model was outlined in a special report (PricewaterhouseCoopers, 2014), which presents three components of the "universe of work": the blue universe, the green universe and the orange universe. These are analyzed according to the involvement of companies and employees, the specifics of employment, as well as the workers' challenges offered by the workplace. 


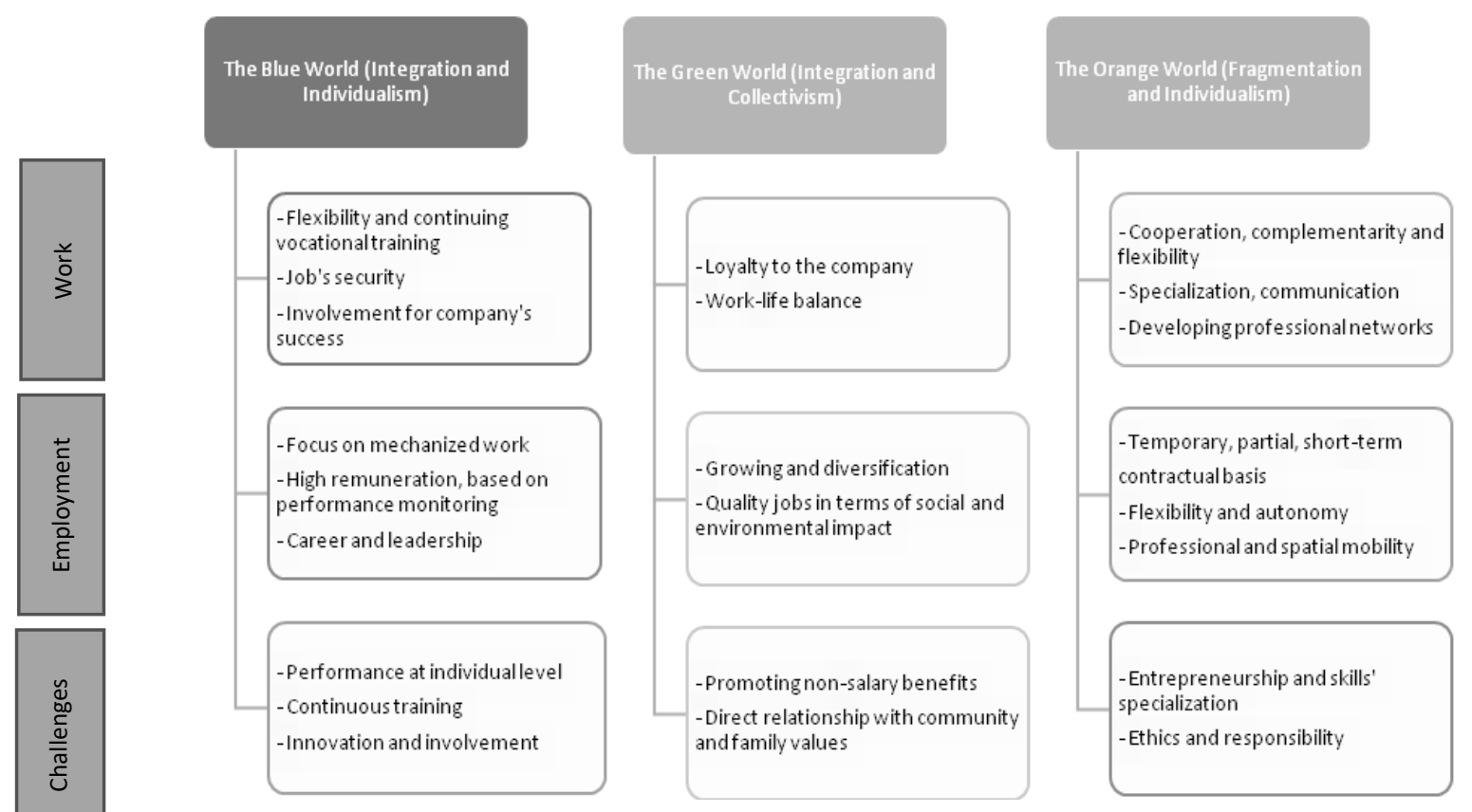

Figure 4. Components of the universe of work in the future

Source: based on PwC (2014) "The future of work - A journey to 2022"

In the blue world, characterized by the syntagma "Corporate is king", companies track the market position, profit, innovation and, at the same time, support demand for consumption. Workers benefit from flexibility in employment and continuous training, but they must be actively involved in the success of the company. Employment is characterized by the emphasis on mechanized work and leadership skills. The remuneration relies on performance, whose monitoring is done on an ongoing basis. Employees' challenges include individual performance, lifelong learning and engagement with the company. All of these are prerequisites for choosing the most profitable job for each individual. In this scenario, the employment flexibility and continuous training are sustaining the human capital valorisation and the qualititative optimal allocation of human capital skills mismatch.

The green world, which has as motto "Caring for Companies", implies loyalty to the company, but also emphasis on the work-life balance. Maintaining the job for long term and sustaining the company's business are the main features. The jobs available are of high quality, from social and environmental perspective, companies practicing corporate social responsibility. Employees are not as concerned with their professional career but rather with their direct relationship with community requirements and family values. Their activity is monitored and pursues performance goals. This approach is supporting the quantitative optimal allocation of human capital - lower vaccancy rate.

The third component of the future work is the orange world, characterized by the phrase "Small is beautiful". It consists of cooperative networks based on specialized small and mediumsized enterprises, aiming to maximize flexibility and minimize fixed costs. Innovation, continuing vocational training and the development and maintenance of professional relationships play important roles. Employment is mainly through atypical forms, i.e. temporary, partial or subcontracting. There may be multiple forms of employment, with the mobility of individuals in both career and territory. This also automatically involves a risk of obtaining permanent income. Individuals have the challenge of creating a portfolio of activities as a result of self-employed status, responsibility for work done, and belonging to professional associations, rather than simply being employed in a company. In the orange world would be possible a compliance between the quantitative and the qualititative optimal allocation of human capital. 
These three components are essential coordinates of the evolution of employment patterns and the valuation of human capital. Some examples of economic activities that will profile on these patterns are: medical professions for blue universe (flexibility in employment, mechanized work), ITC professions for orange world (cooperation, professional networks, temporary employment), and tourism industry for the green world (quality jobs in terms of social and environmental impact, direct relationship with community).

The valuation of human capital will take different positions, depending on the direction (blue, green or orange). The blue world will maintain the employees in a job as part of the security dimension, therefore will assure a permanent and intensive valuation on the labour market. The green world will be oriented on an extensive valuation, by combining work with other elements, such as non-salary benefits, community and family values. Finally, the orange world will adapt the valuation of the human capital on the labour market taking into account some pecularities professional networks, professional and spatial mobility and skills' specialization.

\section{Conclusions}

The concept of human capital has naturally emerged to the need to express the complexity of the elements that define efficient employment. In its very beginning, it referred to the labour force as part of the production process - classical merchant factor. Afterwards the concept added some qualitative attributes, such as division of tasks, performance and linking education with the labor market needs. In the last phase, human capital was emerged into an integrative concept, that includes education, decision-making and skills.

The concept of human capital was analysed from two perspective - as potential starting from the educational market output i.e. the graduates and as real by activation on labour market in any form of capitalisation.

The translation of potential to real perspective, based on mathematical formulas highlighted the particularities of quantitative and qualitative approaches. For future research, the proposed rate of human capital return would be computed, depending on the available datasets from official statistics.

In the future, perspectives on the conceptual development of the human capital rely on the changing nature of work. Even if the valorisation will be quantitative, qualitative or both, will have to consider the changings involved by the fourth industrial revolution, which has imminent effects for the human capital.

\section{References}

1. Eurostat, 2016. Statistical approaches to the measurement of skills, Luxembourg: Publications Office of the European Union.

2. ILO, 1982. Resolutions Concerning Economically Active Population, Employment, Unemployment and Underemployment Adopted by the 13th International Conference of Labour Statisticians, Geneve: ILO.

3. Eurostat. Labour Force Survey, https://ec.europa.eu/eurostat/statisticsexplained/index.php/EU_labour_force_survey_\%E2\%80\%93_data_and_publication\#Main_in dicators_and_EU-LFS_data [Accessed: 10/10/2018]

4. Pisică, S., Vasile, V. \& Voineagu, V., 2012. Piața muncii - între formal și informal. 1 ed. București: Editura Expert.

5. PricewaterhouseCoopers, 2014. The future of work. A journey to 2022, International: PricewaterhouseCoopers.

6. Schultz, T., 1961. Investment in Human Capital. The American Economic Review, 51(1), pp. $1-17$.

7. Taylor, F. W., 1911. The Principles of Scientific Management. 1 ed. New York, NY, US and London, UK: Harper \& Brothers. 
8. Vasile, V., 2016. Particularităţi ale evoluţiei pieţei muncii în Romania. În: Studii de istorie economică şi istoria gândirii economice. București: Editura Academiei Române, pp. 43-82. 